\title{
PENDIDIKAN KARAKTER BERBASIS MANAJEMEN QOLBU DALAM MENGEMBANGKAN KARAKTER RELIGIUS SEBAGAI BAGIAN PENDIDIKAN KEWARGANEGARAAN DI PESANTREN
}

\author{
Budi Putra ${ }^{1}$, Suwarma Al Muchtar ${ }^{2}$ \\ ${ }^{1}$ Departemen Pendidikan Kewarganegaraan, Universitas Pendidikan Indonesia \\ ${ }^{2}$ Departemen Pendidikan Kewarganegaraan, Universitas Pendidikan Indonesia \\ Email : budiraihan79@gmail.com ${ }^{1}$, suwarma@yahoo.com ${ }^{2}$
}

Naskah diterima: 26/03/2018 revisi: 06/04/2018 disetujui: 26/04/2018

\begin{abstract}
Abstrak
Pendidikan karakter paling utama dan bermanfaat untuk membangun kepribadian dan pembentukan masyarakat yang religius dengan konsep manajemen qolbu. Penelitian bertujuan mengkaji dan menganalisis pendidikan karakter berbasis manajemen qolbu dalam mengembangkan karakter religius sebagai bagian Pendidikan Kewarganegaraan di Pesantren Daarut Tauhiid pada program Dauroh Qolbiyah. Pendekatan penelitian yang digunakan yaitu kualitatif dengan teknik pengumpulan data; observasi, wawancara, dan studi dokumentasi. Kesimpulan hasil akhir yang diperoleh dalam penelitian adalah pendidikan karakter berbasis manajemen qolbu adalah suatu pendidikan karakter yang selalu diolah dengan membersihkan hati, ikhlas, jujur, kuat dan tangguh, dengan melakukan pembiasaan ibadah wajib dan sunat, model pembelajaran Ekperiental Learning, Learning by doing. Hati merupakan inti perbuatan manusia. Hati yang suci pasti akan menghasilkan tutur kata, sikap, dan akhlak baik. Dengan begitu akan melahirkan generasi muda yang bermoral dan religius.
\end{abstract}

Kata kunci : pendidikan karakter, manajemen qolbu

\section{CHARACTER EDUCATION BASED ON QOLBU MANAGEMENT IN DEVELOPING RELIGIOUS CHARACTER AS A PART OF CIVIC EDUCATION IN PESANTREN}

\begin{abstract}
Character education is the most important and to build the personality and the formation of a religious society with the concept of Qolbu management. The study aims to examine and analyze character education based on Qolbu management in developing the religious character as part of Citizenship Education in Pesantren Daarut Tauhiid on Dauroh Qolbiyah program. The research approach used is qualitative with data collection technique are observation, interview, and documentation. The conclusion of the final result of this research is character education based on Qolbu management is a character education which is always processed by cleaning the heart and being sincere, honest, strong and tough, by performing obligatory and non-obligatory (sunnah) worships within the framework of experiential learning; in other words, learning by doing. The heart is the essence of human action. A sacred heart will produce good speech, attitude, and good morals. That will give birth to moral and religious youths.
\end{abstract}

Keywords: character education, Qolbu management 


\section{PENDAHULUAN}

\begin{abstract}
Persoalan
karakter sangat memprihatinkan apalagi di kalangan generasi muda, bisa di lihat dari perilaku, sikap dan moral yang semakin terdegradasi dari nilai-nilai keadaban. Megawangi (2004) mengemukakan "...menurunnya kualitas moral bangsa yang dicirikan oleh membudayanya praktek KKN, konflik (antar etnis, agama, politis, remaja, antar RW dsb)..." (hlm. 3). Data Komisi Pemberantas Korupsi menunjukkan pada tahun 2017 tingkat KKN cukup fantastis dibandingkan pada tahun 2016 yakni "penyelidikan 123 perkara, penyidikan 121 perkara, penuntutan 103 perkara, inkracht 84 perkara dan 83 perkara yang sudah dieksekusi"

(https://acch.kpk.go.id/id/statistik/tindakpidana-korupsi diakses Selasa 3 April 2018).

Bagaimana tidak, dalam beberapa tahun terakhir berdasarkan Survei Badan Narkotika Nasional tahun 2016 menunjukkan bahwa pengguna narkoba di kalangan siswa yang mencapai 21.194 orang (11.544 SLTA dan 9.650 SLTP). Fakta tersebut adalah alarm bagi kita untuk bahumembahu menyadarkan dan mengawasi mereka dari barang haram tersebut (Surat Kabar Harian Kedaulatan Rakyat, Selasa 15 Agustus 2017).
\end{abstract}

Pembangunan pendidikan karakter harus dilaksanakan secara menyeluruh oleh berbagai pihak, berawal dari keluarga, sekolah, masyarakat, dan pemerintah. Pendidikan karakter bagian dari pendidikan kewarganegaraan (PKn). PKn tidak hanya pelajaran di sekolah, tetapi juga menjadi pendidikan di masyarakat. Winataputra (2015:153) mengatakan bahwa:

"Pada dasarnya PKn merupakan program pembelajaran yang mengandung keniscayaan bagi suatu negara sebagai wahana pendidikan yang sengaja dibangun untuk membina dan/atau mengembangkan karakter warga negara yang cerdas dan baik (smart and good) dalam latar sub sistem pendidikan formal, pendidikan non formal dan pendidikan informal “

Tujuan pendidikan kewarganegaraan adalah untuk membentuk masyarakat berbudi pekerti, mandiri, profesional, tanggung jawab, dan sehat lahir bathin. Pendidikan kewarganegaraan dapat membentuk sikap yang cerdas, berakhlak dan tanggung jawab. Warga negara harus bertakwa kepada Sang Pencipta dan mengamalkan Pancasila serta melaksanakan hak/kewajiban dengan sebaik-baiknya.

Pasal 3 Undang-undang Republik Indonesia Nomor 20 Tahun 2003 berbunyi:

"Pendidikan nasional berfungsi
mengembangkan dan membentuk watak
serta peradaban bangsa yang martabat
dalam rangka mencerdaskan kehidupan
bangsa, bertujuan untuk berkembangnya
potensi peserta didik agar menjadi
manusia yang beriman dan bertakwa
kepada Tuhan Yang Maha Esa, berakhlak
mulia, sehat, berilmu, cakap, kreatif,
mandiri, yang menjadi warga negara
yang demokratis serta bertanggung
jawab. Pasal 37 ayat (1) kurikulum
pendidikan dasar dan menengah wajib
memuat: ....b. pendidikan
kewarganegaraan;... dan ayat (2)
dikemukakan bahwa kurikulum
pendidikan tinggi wajib memuat:...b.
pendidikan kewarganegaraan..."

Dengan demikian, apabila dilihat dari fokus tujuan pendidikan kewarganegaraan diarahkan pada bidang kajiannya, maka inti ideologi PKn adalah perilaku masyarakat.

Dalam sistem pendidikan nasional sudah jelas tujuan pendidikan bukan untuk mencari nilai semata namun untuk membentuk kepribadian yang berakhlak mulia dan beriman kepada Sang Pencipta. Sejalan dengan ini maka kedudukan guru dan kurikulum menjadi penting dalam 
menciptakan anak didik yang berahklak mulia. Suryadi (dalam Wuryandani dkk, 2014) menjelaskan bahwa krisis moral dan karakter di dunia pendidikan adalah penyebab terjadinya dikotomisasi. Pendidikan lebih menekankan pada kecerdasan otak dan kurang menyentuh aspek emosi dan spiritual yang mengajarkan akhlak, etika, kreatifitas dan ketahanan mental. Hal ini dapat dilihat dalam dunia pendidikan terjadinya jurang pemisah antara ilmu agama dan ilmu lainnya di dunia pendidikan,

Martin Seligman (mantan presiden Amerika psykological assosiations), mengatakan bahwa "orang Amerika yang religius lebih sedikit untuk menyalahgunakan narkoba, melakukan kejahatan, perceraian, dan bunuh diri. Mereka juga secara fisik dalam keadaan lebih sehat dan hidup lebih lama....agama menanamkan harapan untuk masa depan dan menciptakan makna dalam hidup" (Lickona, 2012, hlm. 76).

Pendidikan karakter yang berbasis manajemen qolbu dalam usaha mengembangkan karakter religius merupakan suatu usaha yang dilakukan di pesantren Daarut Tauhiid telah berjalan cukup lama. Manajemen qolbu terdiri dari kata manajemen dan qolbu, "manajemen adalah proses yang berhubungan dengan seluruh usaha manusia baik dibantu orang lain, dengan menggunakan cara atau teknik yang efektif untuk mencapai tujuan" (Hamalik, 2007). Sedangkan "kata qalbu berasal dari bahasa Arab, dari akar kata 'qalaba' - 'yaqlibu' - 'qalban' yang artinya membalikkan, memalingkan, menjadikan yang di atas kebawah yang di dalam keluar" (Yunus, 1989, hlm. 353).

"Ketahuilah, sesungguhnya didalam tubuh terdapat segumpal daging, jika ia baik maka baiklah seluruh tubuh itu dan apabila ia rusak, maka rusaklah badan itu seluruhnya" (Sabda Nabi Muhammad SAW, dalam Qoyyim dan Jauziyyah, 1998, hlm.xxxvi). Jelaslah bahwa baik buruknya manusia itu tergantung dengan hatinya.
Berdasarkan uraian diatas, makna manajemen qolbu adalah proses kegiatan individu untuk menata, mengkondisikan, dan mengatur hati sehingga manusia dapat mencapai kesempurnaan dan berusaha mendapatkan kenikmatan hidup dunia akhirat.

Mencapai hati yang bersih maka dapat diterapkan melalui Empat aktivitas atau tahapan primer, pertama: membebaskan diri dari distorsi dan kompleks psikologi yang menghalangi pembentukan individualitas (kepribadian) yang utuh dan sehat; Kedua: membebaskan diri dari menjadi budak daya tarik dunia; Ketiga: mengangkat tabir yang paling halus dan sifat mementingkan diri; Keempat: memusatkan diri dan semua atensia pada realitas cinta illahiah (Helminski, 2002). Dari tahapan itu kita dapat memusatkan diri dan perhatian kita di hadapan realitas Illahi. Hati yang sadar akan bersedia menerima perbuatan yang salah yang ada pada dirinya dan mau berbuat baik untuk memperbaikinnya, dan dengan ketenangan jiwa hidup akan bahagia, maka dari itu menurut Sultani (2006) ada beberapa macam perbuatan untuk ketenangan jiwa, diantaranya ikhlas, bijaksana, sopan santun, rendah hati, sabar, tawakal, ridha, syukur, jujur, harga diri, menepati janji, prasangka baik, pemaaf, toleran, wara', taqwa, zuhud, semangat.

Upaya yang dapat dilakukan untuk membersihkan hati antara lain: (1) Mengendalikan hati dengan hawa nafsu yang selalu menyelimuti hati; (2) Menjaga potensi hati dengan akhlak-akhlak yang mulia; (3) Menata keikhlasan hati (Gymnastiar, 2004).

"Manajemen qolbu bertujuannya untuk membentuk pribadi muslim yang memiliki aqidah bersih, ibadah yang benar, dan berakhlak mulia, melalui pembiasaan ibadah dan tata cara hidup yang islami, memiliki pemahaman islam, sehingga bermanfaat untuk dirinya dan orang lain" (Gymnastiar, 2004). Konsep manajemen qolbu adalah "mengubah diri, orang lain, dan lingkungan, dengan cara dari diri 
sendiri, hal yang kecil, mulailah sekarang juga" (Gymnastiar, 2004).

Berdasarkan latar belakang, maka rumusan masalah pada artikel ini adalah mengapa pendidikan karakter berbasis menajemen qolbu dapat mengembangkan karakter religius? Tujuan penelitian untuk mengkaji dan menganalisis pendidikan karakter berbasis manajemen qolbu dalam mengembangkan karakter religius sebagai bagian Pendidikan kewarganegaraan pada program Dauroh Qolbiyah.

\section{Jenis Penelitian}

Penelitian memakai pendekatan kualitatif. Penelitian kualitatif yaitu "proses penelitian berdasarkan tradisi metodologi penelitian tertentu dengan cara menyelidiki masalah sosial atau manusia" (Creswell, 2012). Peneliti mendeskripsikan secara detail dan menyeluruh, menganalisis percakapan, melaporkan pendapat nara sumber, dan melaksanakan penelitian dalam situasi alamiah.

\section{Waktu dan Tempat Penelitian}

Penelitian dilaksanakan di Yayasan Daarut Tauhiid Bandung karena satusatunya yang telah melaksanakan manajemen qolbu sejak 1990 dan penerapan program Dauroh Qolbiyah lebih kurang enam tahun. Penelitian dimulai 16 Januari sampai dengan 16 Februari 2018 di Jalan Geger kalong Girang nomor 67, Kelurahan Geger Kalong Kecamatan Sukasari Kota Bandung Provinsi Jawa Barat

\section{Target/Subjek Penelitian}

Subjek penelitian adalah ustad (guru) dan tim pengembang program Dauroh Qolbiyah. Subjek penelitian ini menggunakan teknik purposive. "Purposive adalah penelitian berdasarkan pertimbangan tujuan penelitian, bahwa informan tersebut dapat memberikan informasi yang diperlukan untuk penelitian" (Sugiyono, 2010, hlm. 218).

\section{Prosedur}

Penelitian ini menggunakan pendekatan kualitatif dengan metode studi kasus yaitu peristiwa yang terjadi dan berhubungan dengan kondisi saat ini. Penelitian dengan menggunakan studi kasus memfokuskan perhatian pada permasalahan tertentu sebagai suatu kasus untuk dibahas secara mendalam sehingga dapat melihat kenyataan yang terjadi. Tujuan penggunaan pendekatan kualitatif dengan studi kasus untuk mengetahui fokus penelitian secara real dan mendalam.

\section{Data, Intrumen, dan Teknik Pengumpulan Data}

Pengumpulan data penelitian menggunakan adalah teknik observasi, partisipasi, dokumentasi, dan wawancara.

\section{Teknik Analisis Data}

Analisis data penelitian kualitatif dilakukan dari pengumpulan data di lokasi penelitian dan setelah dari lokasi penelitian. Untuk memperoleh hasil penelitian yang valid, maka ada beberapa proses yang dilakukan peneliti dalam penelitian ini yakni melakukan proses triangulasi dan member check. Triangulasi sumber datanya meliputi pengembang, pengajar (ustad) dan santri pada program Dauroh Qolbiyah di pesantren Daarut Tauhiid Bandung.

\section{HASIL DAN PEMBAHASAN}

Abdullah Gymnastiar mulai mendirikan Daarut Tauhiid (DT) di Gegerkalong Girang tahun 1987, beliau memulai usahanya dengan berwiraswasta yang separoh penghasilannya digunakan pada kegiatan pengajiannya. Yayasan Daarut Tauhiid (DT) secara resmi berdiri tanggal 4 September 1990. Program Managemen Qolbu (MQ) yang telah dilaksanakan berupa kerjasama pendidikan dan pelatihan untuk karyawan dan staff serta eksekutif berbagai perusahaan.

Menurut data observasi tujuan pondok pesantren Daarut tauhiid adalah untuk melahirkan insan profesional yang ahli dzikir, fikir dan ikhtiar. Hal tersebut sejalan dengan pendapat menurut Budimansyah \& Suryadi (2008) sebagai berikut 
Kerangka sistemik PKn dibangun atas dasar: Pertama, PKn secara kurikuler dirancang untuk mengembangkan potensi individu menjadi masyarakat yang berakhlak mulia, cerdas, partisipatif, dan bertanggunggung jawab. Kedua, secara teoritik PKn sebagai subjek pembelajaran yang bermuatan kognitif, afektif, dan psikomotorik dan saling berhubungan dan terintegrasi. Ketiga, secara programatik sebagai mata pelajaran yang menitikberatkan pada nilainilai dan pegetahuan yang diterapkan dalam kehidupan bermasyarakat, berbangsa, dan bernegara (hlm. 63).

Tinjauan filosofis pendidikan $\mathrm{Ki}$ Hajar Dewantara (dalam Komalasari dan Saripudin, 2017) menegaskan bahwa "perilaku berkarakter merupakan perpaduan olah hati, olah pikir, olah rasa dan olah raga. Secara psikologis perilaku berkarakter merupakan perwujudan dari potensi Intelegensi Quotient (IQ), Emotional Quotient (EQ), Sipiritual Quetient ( $S Q)$ dan Adverse Quetient (AQ) yang dimiliki seseorang" (hlm. 5).

Peran seorang tenaga pengajar (ustad) di pesantren menjadi tokoh tauladan dalam kehidupan sehari-hari, nilai karismatik para ustad menjadi acuan dan rujukan bagi masyarakat. Dalam kehidupan di pesantren selalu dilakukan pembinaan keimanan yang sering disejajarkan dengan pembinaan nilai-nilai kepercayaan, sehingga nilai kepercayaan itu menjadi yang paling utama dan pertama dalam hidup, nilai dipandang sebagai sesuatu harga yang memiliki kedudukan yang lebih tinggi. Di lain hal, peran seorang guru atau kyai dalam pendidikan di pesantren sangat menentukan. "Dengan mendengarkan suara hati, karena suara hati adalah pantulan dari fitrah jiwanya. Melalui hati yang baik ia mampu memahami dan mengembangkan dirinya" (Faizin, 2013, hlm. 137). Seluruh kiprahnya untuk keridhoan Allah. Implikasinya dalam pembelajaran adalah terciptanya interaksi yang sangat menyenangkan antar guru/kyai dengan murid.

Konsep Manajemen untuk meraih beningnya hati diantaranya adalah: pertama Mengenal Allah; Ma'rifatullah sebagai landasan hidup, Rasulullah sebagai panutan, meraih hidayah Allah, Zikir: kunci ketenangan hati, tobat nasuha, dzikrul maut. Kedua akhlak mulia; Hati aset berharga, menata keikhlasan hati, menjadi insan penyabar, menjaga pandangan, melatih hidup bersih, paksa diri berbuat taat, menyikapi ujian, ketiga keluarga sakinah; Membangun pendidikan dari keluarga, peran wanita dalam keluarga, memuliakan orang tua, berharganya sikap lembut suami, akhlak kepada pembantu, meminimalkan konflik dalam keluarga, menata kehidupan bertetangga.

Manajemen qolbu untuk meraih sukses membersihkan hati dengan melakukan hal-hal dibawah yang dikenal dengan

Tujuh B dan secara langsung di dimplementasikan dalam kegiatan program Dauroh qolbiyah diantaranya adalah: (1) Beribadah dengan benar: jika hidup tanpa ibadah yang benar ibarat hidup tanpa pondasi, beribadah yang benar akan membuat kita semakin tawadhu (2) Berakhlak mulia: Taat beribadah tetapi tidak menjaga tingkah laku dan perkataan, apalah artinya, kalau tidak dibarengi akhlak mulia. (3) Belajar tiada henti: Akhlak dan ibadah sudah bagus tidak cukup karena semakin tinggi derajat seseorang maka cobaan yang dihadapi akan semakin banyak, orang sukses adalah orang-orang yang cinta ilmu dengan rajin belajar. (4) Bekerja keras dengan cerdas dan ikhlas: standar diri adalah bekerja maksimal dengan cerdas karena kerja keras tanpa berpikir akan percuma. (5) Bersahaja dalam hidup: ada orang yang bekerja keras tetapi sia-sia, karena boros, bermegah-megah, diperdaya orang lain, dan dengki, itu dikarenakan tidak 
bersahaja (6) Bantu sesama: alat ukur sukses adalah punya kelebihan untuk memajukan orang lain. Kesuksesan adalah sejauh mana kita mampu mensukseskan orang lain (7) Bersihkan hati selalu: Allah tidak menerima amal sesorang, kecuali ikhlas dan semuanya karena Allah (Renbang Daarut Tarbiyah, 2015, hlm.161).

Tawadhu, taat kepada Allah, hati menjadi bersih, lurus, dan tentram merupakan dampak ibadah yang sempurna dengan begitu kehidupan akan seimbang dan semakin bernilainya kualitas religius di mata Allah.

Sejalan dengan apa yang diterapkan dalam program Dauroh Qolbiyah, Lickona (2012) mengemukakan bahwa "karakter terdiri atas tiga bagian yang saling terkait, yaitu pengetahuan moral (moral knowing), perasaan moral (moral feeling), dan perilaku bermoral (moral behavior), karakter yang baik mengetahui kebaikan, mencintai atau menginginkan kebaikan, dan melakukan kebaikan" (hal. 82). Cara membentuk karakter yang efektif adalah dengan melibatkan ketiga aspek tersebut.

Dauroh Qolbiyah memiliki kurikulum yang tersusun baik dengan materi untuk pengembangan BAKU (karakter baik dan kuat). Pengembangan karakter BAKU sejalan dengan pendapat (Ajat sudrajat dalam Ainiyah, 2013) bahwasanya "Indikator keberhasilan pendidikan karakter adalah jika seseorang telah mengetahui sesuatu yang baik (knowing the good) bersifat kognitif, kemudian mencintai yang baik (loving the good) bersifat afektif, dan selanjutnya melakukan kebaikan (acting the good) bersifat psikomotorik" (hlm. 37).

Pembelajaran melalui pembiasaan dengan langsung mempraktekkan atau menggunakan metode Ekperiental Learning, Learning by doing). Pembiasaan ditekankan pada konsep Tujuh cinta, Pertama cinta sholat: mengerjakan sholat fardhu lima waktu dan mengerjakan sholat rawatib, qolbiyah bakdiah, sholat sunat tahajud, dhuha dan tarawih secara baik sesuai petunjuk. Kedua cinta shaum, dilaksanakan puasa senin dan kamis. Ketiga cinta zikir, zikir pada pagi dan sore hari dengan menggunakan buku saku (al maksurat) yang sudah dirancang. Ibadah ini sesuai dengan yang dianjurkan Rasulullah Nabi Muhammad SAW. Keempat cinta masjid, pembiasaan yang yang dilakukan dimesjid dengan memakmurkan masjid dengan infak dan shodakoh, itikaf dan tilawah. Kelima cinta ilmu, memperkaya diri dengan pembiasaan kajian ba'da shubuh dan magrib, kajian al kitap serta kegiatan pembelajaran di kelas senin sampai jumat. Keenam cinta al qur'an, pembiasaan tilawah, menghafal serta memperdalam ilmu baca alqur'an karena kalau salah baca maka akan salah makna. Ketujuh cinta sedekah, pembiasaan sedekah mal (harta) sedekah senyum, membantu sesama dan keikhlasan hati untuk memungut sampah.

Konsep Tujuh cinta targetnya adalah Qolbun salim santri, semakin kita mengenal diri kita dan akan mengetahui kekurangankekurangannya, mungkin selama ini kurang ibadah sholat wajib dan sunatnya, puasanya sering lalai dan ibadah lainnya, dengan konsep ini akan menambah kedekatan dan kecintaan santri pada Allah yang ahkirnya akan terasa nikmatnya. Sebagaimana yang dikemukakan oleh Budiyanto dan Machali (2014, hlm. 116) "manusia dianugerahi potensi positif berupa nurani dan negatif berupa nafsu, untuk mengasah potensi positif, yaitu nurani yang merupakan perpaduan akal dengan qolbu, maka perlu adanya pengendalian dan pengelolaan nafsu serta nurani atau olah jiwa". Hal ini direalisasikan dengan pembiasaan seperti para santri dianjurkan melaksanakan tathawwu', puasa Senin dan Kamis, sholat tahajud serta sunnah-sunnah yang dianjurkan Rasullullah.

Berdasar hasil penelitian terungkap bahwa manajemen qolbu dapat mengembangkan karakter religius dengan konsep pembiasaan-pembiasaan dengan slogan Tujuh B dan pembiasaan Tujuh Cinta. Pembiasaan-pembiasaan yang 
dilakukan dalam program Dauroh Qolbiyah untuk membersihkan/meluruskan hati (qolbun salim) guna mengembangkan ketauhiitan kepada Allah. Segala sesuatu berupa keinginan dari seseorang akan tersaring oleh hati sehingga membentuk akhlak mulia yang sangat bermanfaat. Segala bentuk tindakan baik yang positif dan negatif dapat direspon melalui pengelolaan hati yang baik. Dampak qolbu yang terkelola dengan baik akan menghasilkan hal-hal bermanfaat dan jauh dari kemudharatan. Setiap ucapan, perilaku dan kegiatan yang keluar akan tersaring dengan proses menata, mengatur dan mengelola qolbu. Dengan qolbun salim setiap insan akan mendapatkan dan merasakan kenikmatan hidup dunia akhirat. Hasil penelitian ini sesuai dengan apa yang dikatakan Qayyim dan Jauziyyah (1998) bahwa "Qolbun Salim (hati yang bersih, sehat) karena sifat bersih dan sehat telah menyatu dengan hati manusia. Hati yang bersih dan selamat dari berbagai sahwat yang menyalahi perintah dan larangan Allah, bersih dan selamat dari berbagai syubhat" (hlm. 1).

Program Dauroh Qolbiyah menggunakan konsep manajemen qolbu dalam mengembangkan karakter religius sebagai bagian pendidikan kewarganegaraan pada nonformal. Pembentukan watak warga negara sesuai dengan proses pembelajaran program Dauroh qolbiyah yaitu: civic knowledge, civic skill, civic participation. Pengetahuan pendidikan kewarganegaraan dengan program Dauroh Qolbiyah dapat dikembangkan dengan cara mengelola, membersihan hati, pembentukan keterampilan masyarakat dalam praktek Janaiz, dan menumbuhkan kepedulian warga negara untuk memakmurkan masjid (cinta masjid) dalam bentuk kegiatan membangun, menjaga dan merawat masjid.

\section{SIMPULAN DAN SARAN}

\section{Simpulan}

Berdasarkan pada temuan dan pembahasan penelitian dapat diambil kesimpulan pendidikan karakter berbasis manajemen qolbu adalah suatu pendidikan karakter dengan mengatur, mengendalikan, mengontrol dan membersihkan hati, ikhlas, jujur, kuat dan tangguh. Program Dauroh Qolbiyah dengan konsep manajemen qolbu berperan dalam mengembangkan karakter religius sebagai bagian Pendidikan Kewarganegaraan pada jalur pendidikan nonformal. Pengembangan karakter religius melalui pembiasaan-pembiasaan ibadah yang dikenal dengan slogan Tujuh B dan Tujuh Cinta. Karakter religius menjadi prioritas utama untuk dikembangkan melalui nilai moral ketakwaan, kejujuran, keikhlasan, dan tanggungjawab. Model pembelajaran dalam mengembangkan karakter religius adalah Ekperiental Learning, Learning by doing. Rangkaian proses pembelajaran program Dauroh Qolbiyah dapat digunakan untuk pembentukan warga negara yaitu civic knowledge, civic skill, civic participation.

\section{Saran}

Program Dauroh qolbiyah menjadi konsep pengembangan karakter religius bagi pemerintah dan swasta agar tercapai tujuan pendidikan nasional.

\section{DAFTAR PUSTAKA}

Ainiyah, N (2013). Pembentukan Karakter Melalui Pendidikan Agama Islam. Jurnal Studi-studi Islam. 13(1). hlm 25-38

Budimansyah D \& Suryadi K. (2008). PKN dan Masyarakat Multikulural. Bandung: UPI Program Studi Pendidikan Kewarganegaraan

Budiyanto, M. \& Machali, I. (2014). Pembentukan Karakter Mandiri Melalui Pendidikan Agriculture Di Pondok Pesantren Islamic Studies Center Aswaja Lintang Songo Piyungan Bantul Yogyakarta. Jurnal pendidikan Karakter. 6(2). HIm 108-122 
Citizenship Jurnal Pancasila dan Kewarganegaraan Vol 6 No 1 April 2018, hal 63-7o

Avaliable online at : http://e-journal.unipma.ac.id/index.php/Citizenship

Print ISSN: 2302-433X Online ISSN : 2579-5740

Creswell, J. (2012). Educational Research.

United States of America: University of Nebraska.

Faizin, M. (2013). Peran Manajemen Qolbu bagi Pendidik. Jurnal Pendidikan Agama Islam. 1(1). hlm 122-139

Gymnastiar, A. (2004). Meraih bening hati dengan manajemen Qolbu, Jakarta: Gema Insani.

Hamalik, O. (2007). Manajemen Pengembangan Kurikulum, Bandung: PT. Remaja Rosdakarya,

Helminski, K, (2002). Hati yang Bermakrifat. Jakarta: Pustaka Hidayah.

Komalasari, K. \& Saripudin, D. (2017). Pendidikan Karakter Konsep dan aplikasi living Values Eduacation. Bandung: PT. Refika Aditama.

Komisi Pemberantasan Korupsi. (t.t) https://acch.kpk.go.id/id/statistik/ti

ndak-pidana-korupsi diakses Selasa 3 April 2018

Lickona, T. (2012). Educating for Character (Bagaimana Sekolah dapat Memberikan Pendidikan tentang Sikap Hormat dan Tanggung Jawab). Jakarta : Remaja Rosdakarya.

Megawangi, R. (2004). Pendidikan Karakter solusi yang Tepat untuk Membangun Bangsa. Bandung: BPMIGAS dan Energi.

Renbang Daarut Tarbiyah. (2015). Modul Program Dauroh Qolbiyah (DQ). Bandung: Daarut Tauhid

Sugiyono. 2010. Metodologi Penelitian Pendidikan Pendekatan Kualitatif, Kuantitatif $R \& D . \quad$ Bandung: Afabeta.

Sultani, G, R. (2006). Hati yang Bersih. Jakarta: Zahra.

Suwarma, A, M (2015). Dasar Penelitian Kualitatif. Bandung : Gelar Pustaka Mandiri.

Qayyim \& Jauziyyah (1998). Manajemen Qolbu/Melumpuhkan Senjata Syaetan. Bekasi: Darul Falah

Winataputra, U. (2015). Pendidikan Kewarganegaraan Refleksi Historis
Epistemoslogis dan Rekonstruksi Untuk Masa Depan. Tangerang Selatan: Universitas Terbuka Kementerian Riset, Teknologi dan Pendidikan Tinggi.

Wuryandani, dkk. (2014). Internalisasi Nilai Karakter Disiplin melalui Penciptaan Iklim Kelas yang Kondusif di SD Muhammadiyah Sapen. Jurnal Pendidikan Karakter, Tahun IV, No. 2, juni 2014, hlm. $175-184$

Yunus, M. (1989). Kamus Arab-Indonesia, Jakarta: PT Hidakarya Agung.

Undang-undang Republik Indonesia Nomor 20 Tahun 2003 tentang Sistem Pendidikan Nasional. 